\title{
Localization-triggered bacterial pathogenesis
}

\author{
Rolf Lood', Kristofer Wollein Waldetoft ${ }^{1} \&$ Pontus Nordenfelt ${ }^{*, 1}$
}

Bacterial infections are becoming an increasing problem worldwide and there is a need for a deeper understanding of how bacteria turn pathogenic. Here, we suggest that one answer may be found by taking into account the localization of the bacteria, both at an anatomical level and at a microenvironment level. Both commensals and traditional pathogens alter their interaction with the human host depending on the local surroundings - turning either more or less virulent. These localization effects could derive from the characteristics of different anatomical sites but also from local differences within a microenvironment. In order to understand the adaptive functions of bacterial virulence factors, we need to study the bacteria in the environments where they have evolved.

We are all colonized with bacteria, even being outnumbered 10:1 on a cellular level. Despite this fact, we are rarely negatively affected by this colonization, but rather enjoy a commensal, if not mutualistic, interaction with these bacteria. However, most of these commensal bacteria can also be defined as opportunistic pathogens, being able to cause disease once an 'opportunity' arises; whether this opportunity consist of an impaired immune system, dysregulated microbiome, breaches of immunological barriers or changes of localization for the bacteria. Taking such 'opportunities' is not necessarily adaptive for the bacteria, but these factors nevertheless contribute to many clinically important infections.

Opposite to this commensal nature of certain bacteria, others are more pathogenic, causing severe diseases. Even these pathogenic bacteria can act as colonizers of certain habitats without causing disease, or even eliciting an inflammatory immune response.

The classic distinction between pathogens and commensals is focused on genetic differences among bacterial species or strains, while acknowledging the importance of the immune status and other properties of the host. In this paper, we wish to bring a different aspect into focus; we review and appraise the role of localization for the outcome of bacterium-host interactions, the term 'localization' encompassing the entire range from the anatomical to the subcellular (Figure 1).

\section{Commensalism \& the skin microbiome}

We are constantly interacting with our environment, responding to signals generated from a vast number of different sources; both on a cellular level, as well as on a molecular level. The skin, being one of the largest interaction surfaces of the body, is home to a plethora of microorganisms, communicating both between themselves, as well as with their host. Although the skin is inhabited by different classes of microorganisms (e.g., fungi, viruses and bacteria), we will solely focus on bacteria in this review.

'Division of Infection Medicine, Department of Clinical Sciences, Lund University, SE-221 84 Lund, Sweden

*Author for correspondence: Pontus.Nordenfelt@med.lu.se

\section{Future :\%: Medicine ${ }_{\text {part of }}$}

\section{KEYWORDS}

- commensal • evolution

- immune system

- opportunistic pathogen

- pathogen • virulence 


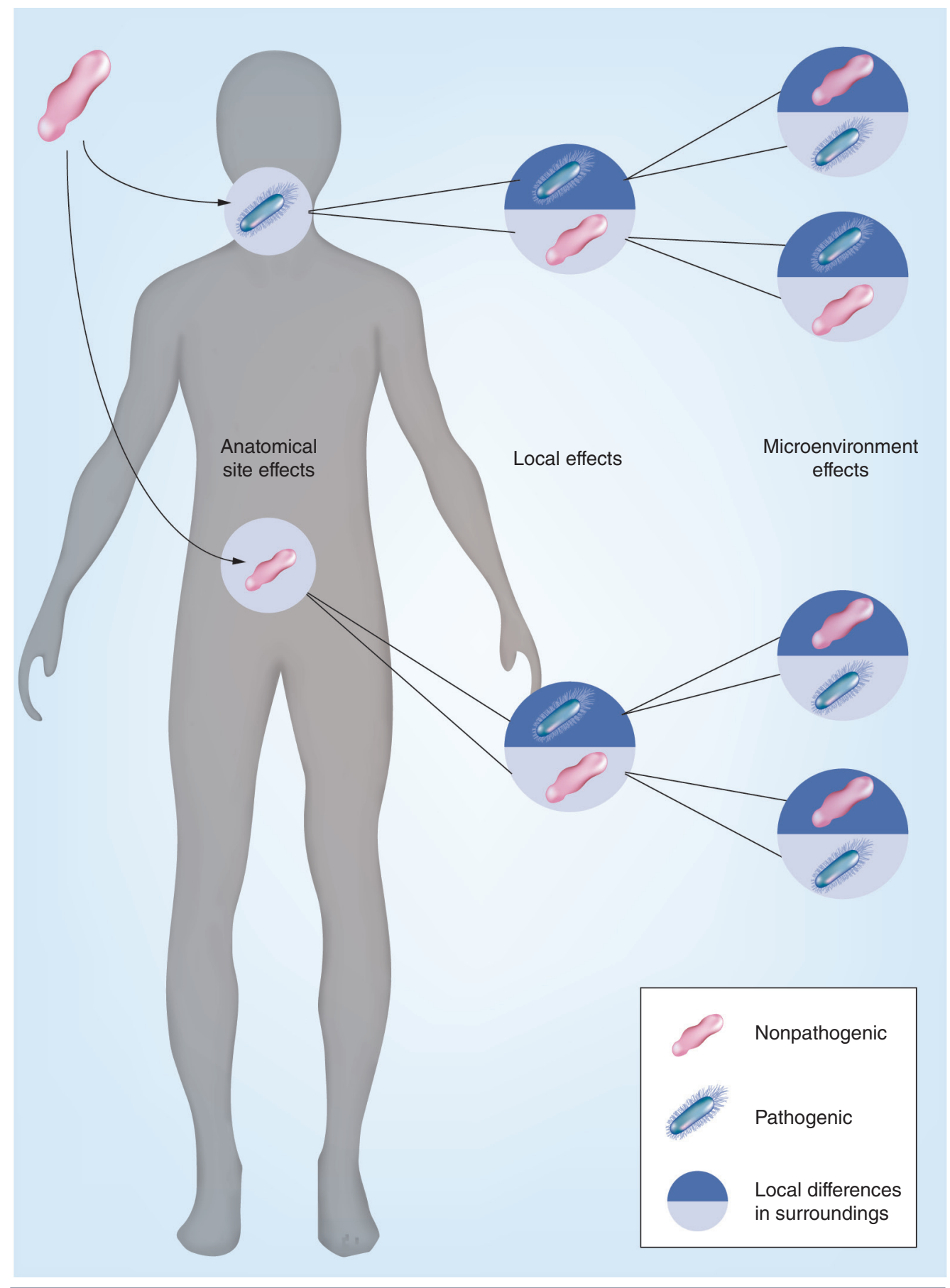

Figure 1. Localization-triggered bacterial pathogenesis. Schematic view of how localization can affect whether a bacterium will be nonpathogenic or pathogenic. A bacterium that enters into two different anatomical sites will behave differently depending on which site it is (e.g., throat vs skin), the specific subsite localization (e.g., inside or outside of host cells), as well as other factors in that particular locale (e.g., molecule concentration).

Several bacteria are commonly isolated (formerly known as Peptostreptococcus magnus) from skin, including Corynebacterium, and Acinetobacter [1,2]. Several of these bacteria Propionibacterium granulosum, Propionibacterium only occasionally colonize the skin, and are preavidum, Staphylococcus aureus, Streptococcus pyogenes, Pseudomonas aeruginosa, Finegoldia magna sent in low numbers. However, the two most predominant skin bacteria are the Gram-positive 
coccus Staphylococcus epidermidis and the Grampositive rod Propionibacterium acnes; colonizing the epidermis and sebaceous glands, respectively [1]. Although the microbiota varies among individuals [3], it is suggested to be rather stable within an individual [4]. While S. epidermidis rarely is associated with skin disease, $P$. acnes is associated with several inflammatory skin diseases, with acne being the most notable [5]. However, its precise role in the development of this disease has not been elucidated [6]. Not only do these two bacteria dominate their respective habitats, but we are all colonized by these skin commensals, reaching levels of $10^{4} \mathrm{cfu} / \mathrm{cm}^{2}$ for $P$. acnes on the forehead [7] and similar levels for $S$. epidermidis on skin [8]. These two bacteria tolerate aerobic as well as anaerobic environments, even though $P$. acnes only grow well under microaerophilic or anaerobic conditions [9]. Despite their prevalence, the commensal nature of these bacteria has not been well studied. Rather, it is their occasional pathogenicity, triggered by a change of localization that has been the main focus of research. Nevertheless, certain aspects of their suggested beneficial aspects have been described.

\section{- Beneficial effects of the skin microbiome}

The beneficial aspects of bacteria have been proven in many systems, not the least in the gastrointestinal tract, with bacteria assisting with our metabolism (vitamin K synthesis) [10], having a positive net effect on the activity of our immune system [11], and protecting from (more) pathogenic bacteria [12]. However, the impact of bacteria on skin has not been as thoroughly investigated. One beneficial aspect of being colonized by skin commensals would be the physical barrier they represent, hindering other more pathogenic bacteria from colonizing. This has been one of the dominating ideas of how skin commensals benefit us. While this certainly has proven correct, and for which we will discuss certain mechanisms, skin commensals have more refined methods to benefit us: protecting us from harmful pathogens, interacting with and modulating our immune system locally.

The sebaceous glands are usually only colonized with $P$. acnes [2], despite the highly nutritional habitat, with a high content of energy-rich sebum. One aspect of this monocolonization might be the ability of $P$. acnes to ferment carbohydrates and produce propionic acid (hence its name). While $P$. acnes is able to tolerate this local reduction in $\mathrm{pH}$, other bacteria lack mechanisms to subsist in that environment. For example, the skin pathogen $S$. aureus, is killed by propionic acid produced by $P$. acnes both in vitro and in vivo in a skin infection model, due to a reduced internal $\mathrm{pH}$ mediated by the increased abundance of propionic acid [13]. Furthermore, $P$. acnes has also been reported to carry genes coding for bacteriocin-like proteins [14]. However, their function and specificity remain to be investigated.

Not all commensal skin bacteria have the ability to produce antimicrobial proteins, such as bacteriocins and antimicrobial peptides (AMPs), by themselves, but can rather process human AMPs to direct the immune system. The skin commensal $F$. magna has been shown, through its cell wall-attached subtilisin protease SufA to be able to cleave the chemokine and AMP MIG (CXCL9). The cleavage products are no longer active against $F$. magna at equimolar concentrations, but retain their antibacterial activity against other pathogenic skin bacteria, including S. pyogenes [15].

Even though S. epidermidis has a wide array of bacteriocins, including phenol-soluble modulins active against the skin pathogens $S$. aureus and $S$. pyogenes [16], most of the research focus regarding its commensal nature has been directed toward its role as an immune modulator, and director, of a proper immune system. As will become clear, the role of S. epidermidis on the skin can be compared with that of a conductor leading an orchestra, directing the proper actions from the different immune cells.

In a 2009 study in Nature it was elegantly described how $S$. epidermidis could specifically modulate the immune response during skin injury and suppress inflammation. Through $S$. epidermidis derived lipoteichoic acid binding to exposed TLR2, TNF $\alpha$ production was suppressed in keratinocytes. Lipopolysaccharide on the other hand could not suppress this effect. Downstream, TLR2 activation lead to TRAF1 processing, TLR 3 inhibition, and thus a lowered inflammatory response, favoring a noninflammatory wound healing [17]. It should however be stressed that only keratinocytes respond in an anti-inflammatory fashion; other immune cells will recognize lipoteichoic acid from S. epidermidis and mediate an inflammatory response.

Furthermore, S. epidermidis has been shown to be critical for the effector T-cell function on skin, through the stimulation of IL-1 $\alpha$ on skin [18]. A follow-up study described on a molecular level the input, and impact, of S. epidermidis 
on the local skin immunity in order to generate an effective immune response against pathogens [19]. Through induction of IL-17A expression, accumulation of effector T-cells localized to the skin and the cooperation of skin-resident dendritic cells, S. epidermidis was able to locally modulate the immune system to a 'unique protective skin immune signature' [19] able to better fight off pathogens, including Candida albicans.

\section{- Commensals turning pathogenic once in a different localization}

Although being classified as skin commensals, despite the fact that $P$. acnes is associated with certain skin diseases (e.g., acne), both P. acnes and $S$. epidermidis have recently been discussed as opportunistic pathogens due to their association with medical implants, in particular venous catheters and joint implants [20,21]. Even though infections caused by these commensals can occur without the presence of medical implants, including endocarditis [22], they are less common. Initially, their association with these conditions was mainly regarded with skepticism, and as agents of contamination due to their high prevalence on skin. However, with refined methods to detect bacteria, through next generation sequencing and multilocus sequence typing, it has been verified that these skin commensals can cause localized low-grade, often chronic, inflammation once attached to medical implants [23]. Reports describe the presence of $P$. acnes in more than $50 \%$ of culture positive samples from patients undergoing revision arthroplasty [24], while $S$. epidermidis still is the most commonly isolated bacterium from foreignbody-related infections [25]. In many cases, these conditions are difficult, if not impossible, to treat with antibiotics. The bacteria themselves have started to develop resistance to many antibiotics, in particular $S$. epidermidis where a high degree of clinical strains have resistance to methicillin and oxacillin [26]. Furthermore, within a biofilm environment, cells can be several magnitudes more resistant to antibiotics than in a planktonic phase [27]. We, and others, have attributed this high number of opportunistic infections to the ability of $P$. acnes and $S$. epidermidis to form rigid biofilms; exopolymer encapsulated formations of bacterial communities. For $P$. acnes it has been shown that invasive strains have an increased biofilm formation [28], and most invasive $S$. epidermidis strains carry the icaADBC cassette, enabling biofilm formation [29], as well as the insertion element IS256, able to modulate the gene expression of virulence factors [30]. The question that then arises is how a commensal turns pathogenic, and if this should be attributed to certain aspects of the bacterium.

\section{- How does a commensal become a pathogen?}

Even though $P$. acnes and $S$. epidermidis both colonize the skin, and cause similar opportunistic pathologies, they are vastly different in terms of genetic variability and ability to adapt to environmental factors. S. epidermidis has a high genetic variability, and can even rearrange its genome within a host during an infection [31]. Certain clones, having the icaADBC cassette and IS256, have been argued to be responsible for causing disease, and these factors thus seem critical [32]. However, taking into account that this lineage is clonal, mathematical models suggest that these factors might not be necessary for causing disease [33].

$P$. acnes is opposite to $S$. epidermidis in terms of its ability to rearrange the genome. On a population level, $P$. acnes is fairly clonal, with a core genome of $88 \%$ [34]. Even though lytic and pseudolysogenic phages have been isolated from $P$. acnes [35,36], no prophages have been detected, thus limiting the amount of mobile genetic elements. Furthermore, no plasmids have been isolated from $P$. acnes, even though reports exist of a Tn5432 transposon containing erm $X$, giving the bacterium erythromycin resistance [37]. Still, on a genomic level, $P$. acnes is very stable and conserved. Certain clones, based on MLST, have been associated with acne [34], but the molecular mechanism behind this still remains to be investigated.

On a genomic level, $P$. acnes is well-equipped with several putative virulence factors, including secreted lipases, proteases and CAMP-factors, being able to induce a strong inflammatory response [38]. S. epidermidis on the other hand has taken a different path, not focusing on degrading host factors, but rather to be able to persist in different environments [32]. Despite these very different backgrounds, both bacteria lead to low-grade local inflammations after the formation of biofilms when exposed to medical implants. The question thus arises why these two commensals have ended up in this localization. Due to their high numbers on skin, it could be argued that this is a numbers game. The likelihood of contaminating a medical implant, 
syringe or catheter with either of these two bacteria is high. Even though, arguably, these bacteria are not adapted to this environment, they still manage to survive and cause disease. It could be argued that $P$. acnes and $S$. epidermidis are only 'accidental' pathogens [32]. By changing localization, factors normally used for a commensal interaction with their host, will find a novel function; but in a milieu not favoring the host, neither the bacterium. Biofilm formation, being a mechanism to asymptomatically colonize the skin for P. acnes [39], will also allow this bacterium to bind to medical implants and thus caused localized chronic inflammation. These 'virulence factors' are thus suggested to not be virulence factors in a classical sense. However, due to a change of milieu, it can lead to a localization-triggered bacterial pathogenesis. Therefore, it is likely that such a notion as being a 'commensal' does not completely apply to any microbe. Bacteria can interact with us in a commensal nature in certain habitats/localization, but when this localization is changed, a new interaction has to be established - be it a pathogenic or commensal interaction.

The skin commensals have evolved a symbiotic relationship with their host, with mutual benefits. However, this interaction is only established on the skin, and as soon as the skin is breached (injury, medical surgery), the immune system will recognize the skin microbiota as pathogens [17], rather than commensals. This would thus be classified as a localization-triggered event. The idea of tissue-based immunological control was recently discussed in an excellent Perspective article in Nature Immunology [40].

Since these bacteria fulfill an important role on the skin, it would be advisable to only treat these infections locally, and not aim for the development of vaccines, since that might skew the skin microbiota, and have nonintended, and unwanted effects.

\section{Pathogens can be commensals}

We have described the scenario for when typical commensals turn pathogenic, but what about the opposite, pathogens behaving as commensals? The distinction between harmless and harmful bacteria might actually be quite difficult and there is a large group of bacteria that could be defined as commensal pathogens [41]. If we look at two of the most prominent human pathogens in that they cause a tremendous amount of infections and deaths $[42,43]-S$. pyogenes and $S$. aureus are commonly found as asymptomatic colonizers in humans. It is estimated that $30-50 \%$ of all humans are colonized by $S$. aureus [43], typically in the skin and mucosal surfaces and most commonly in the form of nasal carriage [44]. Similarly, $S$. pyogenes typically colonizes the throat and skin of humans [45]. What is the trigger for them to change from colonization to infection?

In terms of infections, S. pyogenes - or group A streptococcus - is a strictly human pathogen and a common cause of a wide variety of disorders including pharyngitis, scarlet fever, impetigo, erysipelas as well as rheumatic fever, necrotizing fasciitis, sepsis and toxic shock syndrome $[42,46]$. $S$. aureus is also a common cause for multiple human as well as animal infections, including skin and soft tissue infections, bone and joint infections as well as endocarditis and sepsis [43]. However, when these bacteria are residing in the human body, what can trigger them to actually cause an infection?

Both of these bacteria have a wide array of virulence factors where many of them target antibodies or the complement system [47]. These include IgGFc-binding proteins [48], IgAFcbinding proteins [49,50], IgG proteases [51] and endoglycosidases [52], as well as complement interacting proteins [53-55]. Given their natural habitats in the skin, throat and nose where monomeric antibodies and complement proteins are at very low concentrations it is strange that they have evolved such a large repertoire of counter molecules. One reason could be the influx of plasma proteins during superficial cuts and lesions that occur all the time - additionally, both $S$. aureus and $S$. pyogenes can in fact cause vascular leakage [56,57]. Is this why the pathogens have molecules targeting blood plasma proteins or is the very low concentration in their normal habitat the real target for functionality?

\section{- Localization could be the trigger for pathogenesis}

If you put a pathogen in an environment for which it is not adapted, in most cases it will probably succumb to the immune system or be overcome by other microbes. For instance, we have shown that the IgGFc-binding proteins of $S$. pyogenes only reverse IgG orientation in environments with low concentrations $(\sim 1 \mu \mathrm{g} / \mathrm{ml})$ of antibodies [58] as found in saliva and mucosa. At high concentrations $(-10 \mathrm{mg} / \mathrm{ml})$ such as in blood plasma, IgG is correctly bound and promotes complement deposition and phagocytic 
killing. This was also demonstrated in a patient who had asymptomatic throat colonization at the same time as necrotizing fasciitis and points to the importance of the local composition of effector molecules [58]. In this case, it could be that classic virulence factors such as IgGFc-binding molecules are not exhibiting their adaptive functions during invasive infections, but instead trigger completely different reactions when presented with an abnormal environment.

Some clues might be found in where pathogens tend to colonize. Despite many similarities in their virulence factors, $S$. aurues tends to be found in the nose whereas $S$. pyogenes favors the throat. It could be that careful analysis of the local properties of these environments in terms of molecule concentrations, $\mathrm{pH}$, host cell types, other microbes etc. would reveal part of the answer for this type of tropism; switching the setting might induce a pathogenic behavior in the bacteria. However, the ultimate trigger that will lead to a bacterial infection is likely very challenging to determine. It could very well be a stochastic chain of events influenced by a large number of local factors. Still, if we could solve parts of this equation, it might be easier to predict infections and ultimately to treat them.

One aspect of pathogens that is often neglected is their interactions with other microbes present in the same locale. For example, pathogens are aided by a certain degree of inflammation to spread, and since commensals do not trigger inflammation, pathogens first need to break through the physical barrier that the commensals constitute [59]. On top of that, it is obvious that crowding will cause a general competition for nutrients.

The specific host-pathogen relationship is of great importance. The very same clone that will cause invasive disease in one individual will not affect others, or in many cases this duality could exist within one individual. For example, in $80 \%$ of severe $S$. aureus infections, the individuals were infected with a strain that had already asymptomatically colonized their nose [60]. Also, mixed-culture experiments with Haemophilus influenzae suggest that infections arise from a single bacterium [61]. This supports the notion that changing the local surroundings could transform a commensal pathogen into a disease-causing state. Another report showed that persistent carriers have a higher risk of $S$. aureus infections than noncarriers but a lower risk of bacteremia-related death. [62].

\section{- How does a pathogen differ from a commensal?}

Typically pathogens are defined by their ability to cause harm in their hosts, but since there is such an intricate interplay between host, pathogens and the commensals present (microbiota) - that will ultimately decide whether disease will develop - it can be very difficult to define what a pathogen is [63]. S. pyogenes and S. aureus could even be defined as commensal pathogens [41], since they are continuously present in the human population without causing disease despite being two of the most prominent disease-causing agents in humans.

However you define them, both traditional pathogens and commensals need to overcome the human immune defense, even under noninflammatory circumstances. Perhaps traditional pathogens have evolved a slightly different strategy than commensals when it comes to survival and proliferation. Pathogens could have more mechanisms to handle the immune defense and/ or have the ability to invade human cells. These properties might in the end be what could trigger pathogens to go from colonizing bacteria to disease-causing pathogens. The two pathogens covered here have many ways of avoiding the immune system [47]. Both have the ability to invade epithelial cells [64] by binding to fibronectin and activating $\alpha 5 \beta 1$ integrins that then trigger ruffling and uptake of the bacteria $[65,66]$. Using streptolysin O, S. pyogenes can punch holes in intracellular membranes and escape into the cytosol [67]. This type of intracellular survival also extends to phagocytic uptake as they can survive being internalized by both neutrophils and macrophages $[68,69]$; this has also been shown for $S$. aureus [70]. S. pyogenes appear to interfere with phagosomal maturation, preventing the fusion of granules with bactericidal content [71], as well as blocking phagosomal acidification [72]

An interesting aspect is that of the superantigenic properties of certain bacterial surface proteins. The staphylococcal protein A steers IgG production to target it, and thus only need to handle those type of antibodies [73]. Likewise, the streptococcal $\mathrm{M}$ protein is a superantigen [74] and can also bind IgG [75]. Since both protein A and M protein have the ability to bind IgGFc, is that a way to keep antibodies localized close to these superantigens? However, with the severe side effects of this ability, what evolved as a way to hide can also make the situation much worse for the host if the pathogen ends up in the wrong part of the body. 


\section{Conclusion}

In conclusion, while there are differences between pathogens and commensals in terms of the virulence factors they have and what infections they cause, the consequences of the bacterium-host interactions are decisively localization dependent. For example, asymptomatic carriage of $S$. pyogenes in the upper airways is obviously very different from necrotizing soft tissue infections with the same bacterium, underscoring the role of anatomical localization. However, as discussed above, there may also be important effects of localization at the microscopic level, such that the behavior of single bacterial cells may be affected by their immediate environment on - or inside - human cells. Research on bacterium-host interactions has traditionally focused on invasive body sites, as invasive infections are the most severe. This has resulted in detailed knowledge of the molecular mechanisms involved, but it has left us with a rather rudimentary understanding of the bacteria and the adaptive functions of their virulence factors. This is because invasive infections, with the bacteria reviewed here, are probably dead ends, from which the bacteria do not transmit to new host individuals. Thus, the bacteria used in studies of pathogenic mechanisms - including isolates from invasive infections - have almost exclusively noninvasive infections in their history, and have thus evolved in noninvasive settings. In order to understand why these bacteria have their virulence factors, we need to study them in their normal habitats, and this should apply to both macro- and micro-anatomical levels. Although work on this aspect of bacterial virulence has begun to accumulate [58,76-79], at best, research is still scarce.

\section{Future perspective}

A good place to start in terms of future studies is to analyze the properties of known virulence factors in their natural surroundings, and then compare that function with environments where they cause disease. Also, the general behavior of different bacterial species as they interact with human cells in different microenvironments with or without other microbes, will likely yield valuable information about the triggers that localization confers.

Technical advances have already started to offer us the possibility of very detailed insights into the questions discussed in this review, and in the close future more is destined to arrive. For instance, applying computer vision techniques [80] to live imaging enables tracking of individual bacteria while they are interacting with human cells and/or other microbes. This is likely a viable approach to start addressing questions such as what the normal scenario is for a single bacterium that enters the human body. In live biofilm studies, this type of approach showed that the movement of individual bacteria at the leading edge cleared a path for the rest of the bacterial biofilm [81]. Similar studies of how pathogenic bacteria move and interact with human cells during infection processes would be of great value - and is something that will likely to be achieved within the next few years.

\section{Financial \& competing interests disclosure}

$P$ Nordenfelt is funded by the Swedish Research Council (VR, 524-2014-7344), KW Waldetoft is funded by the Wenner-Gren Foundations and $R$ Lood is funded by the Nanna Svartz Foundation. The authors have no other relevant affiliations or financial involvement with any organization or entity with a financial interest in or financial conflict with the subject matter or materials discussed in the manuscript apart from those disclosed.

No writing assistance was utilized in the production of this manuscript.

\section{EXECUTIVE SUMMARY}

\section{Commensalism \& the skin microbiome}

- Commensal bacteria can benefit the health of their host through both direct (e.g., bacteriocins) and indirect (e.g., immune modulation) mechanisms.

- The notion 'commensal' may not completely apply to any microbe.

\section{Pathogens can be commensals}

- It can be difficult to distinguish between pathogens and commensals.

- Both commensals and traditional pathogens alter their interaction with the human host depending on the local surroundings - turning either more or less virulent.

- These localization effects could derive from the characteristics of different anatomical sites but also from local differences within a microenvironment. 


\section{Open access}

This article is distributed under the terms of the Creative Commons Attribution License 4.0 which permits any use, distribution, and reproduction in any medium, provided the original author(s) and the source are credited. To view a copy of the license, visit http://creativecommons.org/licenses/by/4.0/

\section{References}

Papers of special note have been highlighted as: - of interest; $\bullet \bullet$ of considerable interest

1 Grice EA, Kong HH, Conlan S et al. Topographical and temporal diversity of the human skin microbiome. Science 324(5931), 1190-1192 (2009).

2 Grice EA, Segre JA. The skin microbiome. Nat. Rev. Microbiol. 9(4), 244-253 (2011).

3 Human Microbiome Project Consortium. Structure, function and diversity of the healthy human microbiome. Nature 486(7402), 207-214 (2012).

4 Schommer NN, Gallo RL. Structure and function of the human skin microbiome. Trends Microbiol. 21(12), 660-668 (2013).

5 Beylot C, Auffret N, Poli F et al. Propionibacterium acnes: an update on its role in the pathogenesis of acne. J. Eur. Acad. Dermatol. Venereol. 28(3), 271-278 (2014).

6 Bhate K, Williams HC. Epidemiology of acne vulgaris. Br. J. Dermatol. 168(3), 474-485 (2013).

7 Somerville DA, Murphy CT. Quantitation of Corynebacterium acnes on healthy human skin. J. Invest. Dermatol. 60 (4), 231-233 (1973).

8 Noble WC, Pitcher DG. Microbial ecology of the human skin. In: Advances in Microbial Ecology. Alexander M (Ed.). Plenum Press, NY, USA, 245-289 (1978).

9 Dekio I, Culak R, Fang M, Ball G, Gharbia $S$, Shah HN. Correlation between phylogroups and intracellular proteomes of Propionibacterium acnes and differences in the protein expression profiles between anaerobically and aerobically grown cells. Biomed. Res. Int. 2013151797 (2013).

10 Zhang Y-J, Li S, Gan R-Y, Zhou T, Xu D-P, Li H-B. Impacts of gut bacteria on human health and diseases. Int. J. Mol. Sci. 16(4), 7493-7519 (2015).

11 Min YW, Rhee P-L. The role of microbiota on the gut immunology. Clin. Ther. 37(5), 968-975 (2015).

12 Stecher B, Hardt W-D. Mechanisms controlling pathogen colonization of the gut. Curr. Opin. Microbiol. 14(1), 82-91 (2011).
13 Shu M, Wang Y, Yu J et al. Fermentation of Propionibacterium acnes a commensal bacterium in the human skin microbiome, as skin probiotics against methicillin-resistant Staphylococcus aureus. PLoS One 8(2), e55380 (2013).

14 Brüggemann H, Lomholt HB, Kilian M. The flexible gene pool of Propionibacterium acnes. Mob. Genet. Elements 2(3), 145-148 (2012).

15 Karlsson C, Eliasson M, Olin AI et al. SufA of the opportunistic pathogen Finegoldia magna modulates actions of the antibacterial chemokine MIG/CXCL9, promoting bacterial survival during epithelial inflammation. J. Biol. Chem. 284(43), 29499-29508 (2009).

16 Cogen AL, Yamasaki K, Sanchez KM et al. Selective antimicrobial action is provided by phenol-soluble modulins derived from Staphylococcus epidermidis a normal resident of the skin. J. Invest. Dermatol. 130(1), 192-200 (2010).

17 Lai Y, Di Nardo A, Nakatsuji T et al. Commensal bacteria regulate Toll-like receptor 3-dependent inflammation after skin injury. Nat. Med. 15(12), 1377-1382 (2009).

18 Naik S, Bouladoux N, Wilhelm C et al. Compartmentalized control of skin immunity by resident commensals. Science 337(6098), 1115-1119 (2012).

- Demonstrates how the immune system is regulated by skin commensals.

19 Naik S, Bouladoux N, Linehan JL et al. Commensal-dendritic-cell interaction specifies a unique protective skin immune signature. Nature 520(7545), 104-108 (2015).

-• Reveals how specific skin commensals regulate the immune system and help to protect the skin against certain pathogens.

20 Uçkay I, Pittet D, Vaudaux P, Sax H, Lew D, Waldvogel F. Foreign body infections due to Staphylococcus epidermidis. Ann. Med. 41(2), 109-119 (2009).

21 Achermann Y, Goldstein EJC, Coenye T, Shirtliff ME. Propionibacterium acnes: from commensal to opportunistic biofilmassociated implant pathogen. Clin. Microbiol. Rev. 27(3), 419-440 (2014).

22 Monk AB, Boundy S, Chu VH et al. Analysis of the genotype and virulence of Staphylococcus epidermidis isolates from patients with infective endocarditis. Infect. Immun. 76(11), 5127-5132 (2008).

23 Portillo ME, Corvec S, Borens O, Trampuz A. Propionibacterium acnes: an underestimated pathogen in implantassociated infections. Biomed. Res. Int. 2013 804391 (2013)
24 Butler-Wu SM, Burns EM, Pottinger PS et al. Optimization of periprosthetic culture for diagnosis of Propionibacterium acnes prosthetic joint infection. J. Clin. Microbiol. 49(7), 2490-2495 (2011).

25 Eiff von C, Jansen B, Kohnen W, Becker K. Infections associated with medical devices: pathogenesis, management and prophylaxis. Drugs 65(2), 179-214 (2005).

26 Eiff von C, Reinert RR, Kresken M, Brauers J, Hafner D, Peters G. Nationwide German multicenter study on prevalence of antibiotic resistance in staphylococcal bloodstream isolates and comparative in vitro activities of quinupristin-dalfopristin. J. Clin. Microbiol. 38(8), 2819-2823 (2000).

27 Furustrand Tafin U, Corvec S, Betrisey B, Zimmerli W, Trampuz A. Role of rifampin against Propionibacterium acnes biofilm in vitro and in an experimental foreign-body infection model. Antimicrob. Agents Chemother. 56(4), 1885-1891 (2012).

28 Holmberg A, Lood R, Mörgelin M et al. Biofilm formation by Propionibacterium acnes is a characteristic of invasive isolates. Clin. Microbiol. Infect. 15(8), 787-795 (2009).

29 Kozitskaya S, Olson ME, Fey PD, Witte W, Ohlsen K, Ziebuhr W. Clonal analysis of Staphylococcus epidermidis isolates carrying or lacking biofilm-mediating genes by multilocus sequence typing. J. Clin. Microbiol. 43(9), 4751-4757 (2005).

30 Ziebuhr W, Krimmer V, Rachid S, Lössner I, Götz F, Hacker J. A novel mechanism of phase variation of virulence in Staphylococcus epidermidis: evidence for control of the polysaccharide intercellular adhesin synthesis by alternating insertion and excision of the insertion sequence element IS256. Mol. Microbiol. 32(2), 345-356 (1999).

31 Galdbart JO, Morvan A, Desplaces N, el Solh N. Phenotypic and genomic variation among Staphylococcus epidermidis strains infecting joint prostheses. J. Clin. Microbiol. 37(5), 1306-1312 (1999).

32 Otto M. Staphylococcus epidermidis - the 'accidental' pathogen. Nat. Rev. Microbiol. 7(8), 555-567 (2009).

- An interesting perspective on how virulence factors might have an impact even during the commensal life style of opportunistic pathogens.

33 Rohde H, Kalitzky M, Kröger N et al. Detection of virulence-associated genes not useful for discriminating between invasive and commensal Staphylococcus epidermidis strains from a bone marrow transplant unit. J. Clin. Microbiol. 42(12), 5614-5619 (2004). 
34 Tomida S, Nguyen L, Chiu B-H et al. Pan-genome and comparative genome analyses of Propionibacterium acnes reveal its genomic diversity in the healthy and diseased human skin microbiome. MBio 4(3), e00003-13 (2013).

35 Lood R, Collin M. Characterization and genome sequencing of two Propionibacterium acnes phages displaying pseudolysogeny. BMC Genomics 12(1), 198 (2011).

36 Lood R, Mörgelin M, Holmberg A, Rasmussen M, Collin M. Inducible Siphoviruses in superficial and deep tissue isolates of Propionibacterium acnes. BMC Microbiol. 8(1), 139 (2008).

37 Ross JI, Eady EA, Carnegie E, Cove JH. Detection of transposon Tn5432-mediated macrolide-lincosamide-streptogramin B (MLSB) resistance in cutaneous propionibacteria from six European cities. J. Antimicrob. Chemother. 49(1), 165-168 (2002).

38 Brüggemann H. Insights in the pathogenic potential of Propionibacterium acnes from its complete genome. Semin. Cutan. Med. Surg. 24(2), 67-72 (2005).

39 Jahns AC, Alexeyev OA. Three dimensional distribution of Propionibacterium acnes biofilms in human skin. Exp. Dermatol. 23(9), 687-689 (2014).

40 Matzinger P, Kamala T. Tissue-based class control: the other side of tolerance. Nat. Rev. Immunol. 11(3), 221-230 (2011).

41 Henriques Normark B, Normark S. Commensal pathogens, with a focus on Streptococcus pneumoniae and interactions with the human host. Exp. Cell Res. 316(8), 1408-1414 (2010).

42 Carapetis JR, Steer AC, Mulholland EK, Weber M. The global burden of group A streptococcal diseases. Lancet Infect. Dis. 5(11), 685-694 (2005).

43 Lowy FD. Staphylococcus aureus infections. N. Engl. J. Med. 339(8), 520-532 (1998).

44 Wertheim HFL, Melles DC, Vos MC et al. The role of nasal carriage in Staphylococcus aureus infections. Lancet Infect. Dis. 5(12), 751-762 (2005).

45 Cunningham MW. Pathogenesis of group A streptococcal infections and their sequelae. Adv. Exp. Med. Biol. 609, 29-42 (2008).

46 Cunningham MW. Pathogenesis of group A streptococcal infections. Clin. Microbiol. Rev. 13(3), 470-511 (2000).

47 Okumura CYM, Nizet V. Subterfuge and Sabotage: evasion of host innate defenses by invasive Gram-positive bacterial pathogens. Annu. Rev. Microbiol. 68, 439-458 (2014).
48 Nordenfelt P, Björck L. IgG-binding bacterial proteins and pathogenesis. Future Microbiol. 8, 299-301 (2013).

49 Lindahl G, Stenberg L. Binding of IgA and/ or $\mathrm{IgG}$ is a common property among clinical isolates of group A streptococci. Epidemiol. Infect. 105(1), 87-93 (1990).

50 Langley R, Wines B, Willoughby N, Basu I, Proft T, Fraser JD. The staphylococcal superantigen-like protein 7 binds $\operatorname{IgA}$ and complement C5 and inhibits IgA-Fc alpha RI binding and serum killing of bacteria. J. Immunol. 174(5), 2926-2933 (2005).

51 Pawel-Rammingen von U, Johansson BP, Björck L. IdeS, a novel streptococcal cysteine proteinase with unique specificity for immunoglobulin G. EMBO J. 21(7), 1607-1615 (2002).

52 Collin M, Olsén A. EndoS, a novel secreted protein from Streptococcus pyogenes with endoglycosidase activity on human $\mathrm{IgG}$. EMBO J. 20(12), 3046-3055 (2001).

53 Hammel M, Sfyroera G, Ricklin D, Magotti P, Lambris JD, Geisbrecht BV. A structural basis for complement inhibition by Staphylococcus aureus. Nat. Immunol. 8(4), 430-437 (2007).

54 Garcia BL, Summers BJ, Ramyar KX et al. A structurally dynamic $\mathrm{N}$-terminal helix is a key functional determinant in staphylococcal complement inhibitor (SCIN) proteins. J. Biol. Chem. 288(4), 2870-2881 (2013).

55 Åkesson P, Sjöholm AG, Björck L. Protein SIC, a novel extracellular protein of Streptococcus pyogenes interfering with complement function. J. Biol. Chem. 271(2), 1081-1088 (1996).

56 Imamura T, Tanase S, Szmyd G, Kozik A, Travis J, Potempa J. Induction of vascular leakage through release of bradykinin and a novel kinin by cysteine proteinases from Staphylococcus aureus. J. Exp. Med. 201(10), 1669-1676 (2005).

57 Herwald H, Cramer H, Mörgelin M et al. $\mathrm{M}$ protein, a classical bacterial virulence determinant, forms complexes with fibrinogen that induce vascular leakage. Cell 116(3), 367-379 (2004).

58 Nordenfelt P, Waldemarson S, Linder A et al. Antibody orientation at bacterial surfaces is related to invasive infection. J. Exp. Med. 209(13), 2367-2381 (2012).

-• Reveals the critical importance of localization for the function of IgGFcbinding proteins and how that relates to infection.

59 Pédron T, Sansonetti P. Commensals, bacterial pathogens and intestinal inflammation: an intriguing ménage à trois. Cell Host Microbe 3(6), 344-347 (2008).

60 Eiff von C, Becker K, Machka K, Stammer H, Peters G. Nasal carriage as a source of Staphylococcus aureus bacteremia. Study Group. N. Engl. J. Med. 344(1), 11-16 (2001).

61 Moxon ER, Murphy PA. Haemophilus influenzae bacteremia and meningitis resulting from survival of a single organism. Proc. Natl Acad. Sci. USA 75(3), 1534-1536 (1978).

62 Verkaik NJ, de Vogel CP, Boelens HA et al. Anti-staphylococcal humoral immune response in persistent nasal carriers and noncarriers of Staphylococcus aureus. J. Infect. Dis. 199(5), 625-632 (2009).

63 Pirofski L-A, Casadevall A. Q and A: what is a pathogen? A question that begs the point. BMC Biol. 10(1), 6 (2012).

64 LaPenta D, Rubens C, Chi E, Cleary PP. Group A streptococci efficiently invade human respiratory epithelial cells. Proc. Natl Acad. Sci. USA 91(25), 12115-12119 (1994).

65 Rezcallah MS, Hodges K, Gill DB, Atkinson JP, Wang B, Cleary PP. Engagement of CD46 and alpha5betal integrin by group $A$ streptococci is required for efficient invasion of epithelial cells. Cell Microbiol. 7(5), 645-653 (2005).

66 Sinha B, François PP, Nüsse O et al. Fibronectin-binding protein acts as Staphylococcus aureus invasin via fibronectin bridging to integrin alpha5beta1. Cell Microbiol. 1(2), 101-117 (1999).

67 Håkansson A, Bentley CC, Shakhnovic EA, Wessels MR. Cytolysin-dependent evasion of lysosomal killing. Proc. Natl Acad. Sci. USA 102(14), 5192-5197 (2005).

68 Staali L, Mörgelin M, Björck L, Tapper H. Streptococcus pyogenes expressing $\mathrm{M}$ and M-like surface proteins are phagocytosed but survive inside human neutrophils. Cell Microbiol. 5(4), 253-265 (2003).

69 Thulin P, Johansson L, Low DE et al. Viable group A streptococci in macrophages during acute soft tissue infection. PLoS Med. 3(3), e53 (2006).

70 Gresham HD, Lowrance JH, Caver TE, Wilson BS, Cheung AL, Lindberg FP. Survival of Staphylococcus aureus inside neutrophils contributes to infection. J. Immunol. 164(7), 3713-3722 (2000).

71 Nordenfelt P, Winberg ME, Lönnbro P, Rasmusson B, Tapper H. Different requirements for early and late phases of azurophilic granule-phagosome fusion. Traffic 10(12), 1881-1893 (2009). 
72 Nordenfelt P, Grinstein S, Björck L, Tapper $\mathrm{H}$. V-ATPase-mediated phagosomal acidification is impaired by Streptococcus pyogenes through Mga-regulated surface proteins. Microbes Infect. (2012).

73 Pauli NT, Kim HK, Falugi F et al. Staphylococcus aureus infection induces protein A-mediated immune evasion in humans. J. Exp. Med. 211(12), 2331-2339 (2014).

74 Tomai M, Kotb M, Majumdar G, Beachey EH. Superantigenicity of streptococcal M protein. J. Exp. Med. 172(1), 359-362 (1990).

75 Akesson P, Schmidt KH, Cooney J, Björck L. $\mathrm{M} 1$ protein and protein $\mathrm{H}$ : IgGFc- and albumin-binding streptococcal surface proteins encoded by adjacent genes. Biochem J. 300(Pt 3), 877-886 (1994).
76 Wollein Waldetoft K, Råberg L. To harm or not to harm? On the evolution and expression of virulence in group A streptococci. Trends Microbiol. 22(1), 7-13 (2014).

77 Lysenko ES, Lijek RS, Brown SP, Weiser JN Within-host competition drives selection for the capsule virulence determinant of Streptococcus pneumoniae. Curr. Biol. 20(13), 1222-1226 (2010).

78 Lysenko ES, Ratner AJ, Nelson AL, Weiser $\mathrm{JN}$. The role of innate immune responses in the outcome of interspecies competition for colonization of mucosal surfaces. PLoS Pathog. 1(1), e1 (2005).

79 Kasper KJ, Zeppa JJ, Wakabayashi AT et al. Bacterial superantigens promote acute nasopharyngeal infection by Streptococcus pyogenes in a human MHC Class II-dependent manner. PLoS Pathog. 10(5), e1004155 (2014).

- Describes a function of a streptococcal superantigen in upper airway infection.

80 Danuser G. Computer vision in cell biology. Cell 147(5), 973-978 (2011).

81 Gloag ES, Turnbull L, Huang A et al. Self-organization of bacterial biofilms is facilitated by extracellular DNA. Proc. Natl Acad. Sci. USA 110 (28), 11541-11546 (2013).

- This paper is one of the very few examples where the individual behavior of bacteria is studied and shows the promise of modern analysis techniques. 